\title{
LA DICTADURA MILITAR EN LA HISTORIA OFICIAL DEL PSICOANÁLISIS CHILENO: SOBRE LA CONSTRUCCIÓN DE UN PATHOS DISCURSIVO
}

\author{
Esteban Radiszcz \\ Departamento de Psicología de la Universidad de Chile. \\ Unidad de Historia y Psicoanálisis del Programa de Estudios Psicoanalíticos: «Clínica y Cultura» de la \\ Facultad de Ciencias Sociales de la Universidad de Chile. \\ radiszcz@gmail.com \\ Mara Sabrovsky \\ Unidad de Historia y Psicoanálisis del Programa de Estudios Psicoanalíticos: «Clínica y Cultura» de la \\ Facultad de Ciencias Sociales de la Universidad de Chile. \\ marasabro@gmail.com

\section{Silvana Vetö} \\ Escuela de Psicología Universidad ARCIS y Universidad Andrés Bello. \\ Unidad de Historia y Psicoanálisis del Programa de Estudios Psicoanalíticos: «Clínica y Cultura» de la \\ Facultad de Ciencias Sociales de la Universidad de Chile. \\ silvana.veto@gmail.com
}

Recibido: 4 noviembre 2013; Aceptado: 18 febrero 2014

Cómo citar este artículo/Citation: Radiszcz, Esteban; Sabrovsky, Mara y Vetö, Silvana (2014), «La dictadura militar en la historia oficial del psicoanálisis chileno: sobre la construcción de un pathos discursivo», Asclepio 66 (1): p37. doi: http://dx.doi.org/10.3989/asclepio.2014.11

RESUMEN: A partir del análisis de una controversia suscitada en los preparativos del Congreso de la Asociación Psicoanalítica Internacional, realizado en Santiago de Chile en julio de 1999, este artículo intenta trazar los modos en los que la dictadura militar de Pinochet aparece en el corpus de textos con vocación histórica producidos en el seno de la Asociación Psicoanalítica Chilena. Se revela, así, la construcción de un pathos discursivo, caracterizado por la negación, la búsqueda apresurada del consenso y el eufemismo, que sin embargo no sólo nace de los fantasmas de la única sociedad psicoanalítica local de la época, sino que se alimenta de las políticas institucionales implementadas por la asociación internacional a partir del nazismo y por la retórica de la reconciliación elaborada en Chile desde la recuperación de la democracia.

PALABRAS CLAVE: Historia del Psicoanálisis; Dictadura Militar; Políticas del Psicoanálisis; Pathos Discursivo; Chile.

\section{THE MILITARY DICTATORSHIP IN THE OFFICIAL HISTORY OF CHILEAN PSYCHOANALYSIS: ON THE CONSTRUCTION OF A DISCURSIVE PATHOS}

ABSTRACT: Drawing from the analysis of a controversy developed before the Congress of the International Psychoanalytical Association, held in Santiago, Chile, in 1999, this article attempts to retrace the ways in which the military dictatorship appears in the corpus of texts with historical inspiration produced within the Chilean Psychoanalytical Association. The building of a discursive pathos is thus revealed, characterized by denial, hasty search for consensus and the use of euphemisms. Nevertheless, not only from the ghosts of the local psychoanalytic society is this pathos constructed. It also feeds on institutional policies implemented by the International Association since Nazism and on the rhetoric of reconciliation elaborated in Chile since the recovery of democracy.

KEY WORDS: History of Psychoanalysis; Military Dictatorship; Politics of Psychoanalysis; Discursive Pathos; Chile.

Copyright: () 2014 CSIC. Este es un artículo de acceso abierto distribuido bajo los términos de la licencia Creative Commons Attribution-Non Commercial (by-nc) Spain 3.0. 


\section{INTRODUCCIÓN}

Con más de un siglo de existencia en Chile, el psicoanálisis ha sido parte de la vida cultural de este país y ha mantenido fecundos intercambios con disciplinas afines. Durante dicho periodo, los chilenos se vieron confrontados a variados escenarios conflictivos, en los que toda la trama de pensamientos y discursos fue intensamente afectada. Entre éstas situaciones, una de las más radicales fue, sin duda, la dictadura cívicomilitar encabezada por Augusto Pinochet, donde trasformaciones en prácticamente todos los aspectos de la sociedad chilena estuvieron presididas por la violencia sistemática y el terrorismo de Estado.

Fundada en 1949 en ocasión de su reconocimiento por la International Psychoanalitical Association (IPA), la Asociación Psicoanalítica Chilena (APCh) contaba con 24 años para el golpe de Estado de 1973. Hasta 1989, fue la única agrupación de psicoanalistas en Chile, de suerte que, durante toda la dictadura, ella concentró lo principal de la reflexión chilena en psicoanálisis, además del conjunto de la formación disciplinar.

Durante la década de 1960, la presencia de psicoanalistas en universidades y hospitales chilenos disminuyó ostensiblemente, produciéndose un repliegue hacia la Asociación y las consultas particulares. En efecto, la partida hacia el extranjero de relevantes psicoanalistas nacionales insertos en medios académicos y en los servicios públicos de salud, la aparición de importantes rencillas internas y un creciente interés (ideológico, por cierto) en preservar el "oro puro» del psicoanálisis, entre otras muchas razones, determinaron una progresiva tendencia al "encierro" por parte de la mayoría de los psicoanalistas chilenos de aquella época (Whiting, 1980; Arrué, 1988; Florenzano, 1988; Gomberoff, 1990). Así, paulatinamente, la transmisión del psicoanálisis adquirió un énfasis casi exclusivamente clínico y privado, desatendiendo sus aplicaciones a otros ámbitos, la interlocución con otros saberes y, sobre todo, la mantención de un diálogo con lo político y lo social. Para Chile, los sesenta fueron tiempos de grandes transformaciones sociales, pero salvo contadas excepciones (como lo fue el Servicio de Psiquiatría Infanto-Juvenil del Hospital Luis Calvo Mackenna), la APCh parece haberse restado de ellas como institución. Durante el breve gobierno de la Unidad Popular (UP), de noviembre de 1970 a septiembre de 1973, hubo algunas iniciativas de apertura social que no alcanzaron a cristalizarse, de modo que, luego del golpe, la Asociación prosiguió inalterada con su retiro.

Consistentemente, durante toda la dictadura y a pesar de los efectos que la represión política pudo tener sobre ella y sus miembros, la APCh se mantuvo silente e intentó continuar como si nada hubiese sucedido.
Se omitió, entonces, una lectura acerca del conflicto social y político, como también se eludió -incluso después del retorno a la democracia- una discusión mayor sobre la situación del psicoanálisis en condiciones dictatoriales. El relato histórico del psicoanálisis chileno que, construido al alero de la APCh durante la década de 1980, devino en historia oficial, no fue una excepción en tal sentido.

Este escrito busca abordar las formas en que la dictadura aparece (o no), en este corpus de textos con vocación histórica, intentando recuperar los distintos artefactos y estrategias que han participado en su insistente descuido (a veces, decidido silencio), respecto de las condiciones sociopolíticas de aquel entonces. Como veremos, en ellos se formula un relato donde las omisiones, los escamoteos y las distorsiones resultan dependientes del impacto de un punto bien preciso que, estando vinculado a la dictadura de Pinochet, aparece desdibujado o desplazado en lo explícito. Se trataría, en consecuencia, de un corpus de textos históricos cuyos silencios, deformaciones y ambigüedades conformarían un pathos discursivo, en el entendido que la idea de pathos alude al efecto de las pasiones que atraviesan el discurso y convencen, no por la razón, sino por la afectación, la emoción.

En efecto, según Barthes (2004) el pathos se relaciona con «lo que se experimenta, por oposición a lo que se hace; y también por oposición a he pathe: lo pasivo» (p. 124). Concierne aquello que surge de la experiencia, pero no en el sentido de lo que embarga, al modo del trauma, sin preparación; pues "ese poder de ser afectado no significa necesariamente pasividad, sino afectividad, sensibilidad, sentimiento» (p. 128). Así, lo que hallaríamos en la historia oficial de la APCh en tanto discurso sobre la dictadura, no sería a nuestro juicio una producción de la razón, es decir una acción acompañada por la voluntad que construye un relato; sino un discurso afectado, patho-logizado, ensamblado con fragmentos de una emoción reprimida, con intermitencias de la historia, con agujeros de la memoria.

\section{UN POLÉMICO EPISODIO POST-DICTATORIAL}

Comencemos por un controvertido incidente que, ocurrido casi diez años después de la recuperación de la democracia, constituye lo que podría designarse como el cierre del siglo XX del psicoanálisis chileno. Se trata de un significativo episodio que, conteniendo las mismas ambigüedades del relato histórico oficial, confrontó a la única institución psicoanalítica chilena en tiempos de dictadura con aquello que, incluso mucho tiempo después, no había podido propiamente enfrentar y que, aún hoy, no pareciera encontrarse enteramente resuelto.

Durante 1998, en ocasión de los preparativos del 41 o Congreso Internacional de Psicoanálisis a realizarse el 
año siguiente en Santiago, la APCh se encontró envuelta en una ácida polémica desatada por la publicación de un texto de Omar Arrué (1998a) en el Newsletter de la IPA. Buscando dar a conocer la historia reciente del país, el breve artículo comenzaba con una celebración de la estabilidad política y de la floreciente economía nacional, además de recurrir a algunos lugares comunes concernientes a las bondades del terruño, el carácter de su pueblo, sus aguerridos orígenes e, incluso, su baile nacional. El escrito proseguía con una caracterización del contexto político progresista que, bajo la influencia de la revolución cubana, los movimientos juveniles europeos y la doctrina social de la Iglesia Católica, se desarrolló bajo la administración de Frei Montalva, mencionando la reforma universitaria y los inicios de la reforma agraria. Entonces, se relataban los pormenores de la llegada de Allende a la presidencia de la República, para proseguir con una descripción de las circunstancias que se encontraron presuntamente al origen de la conflictividad sociopolítica que habrían conducido al golpe militar de 1973, el cual habría sido -según el autor- esperado por «casi todos los sectores de la población [...] aunque por diferentes razones y con distintos intereses y expectativas» (p. 35). A continuación se narraba el bombardeo del palacio presidencial y se consignaba el suicidio del Presidente Allende. Se señalaba que los militares buscaron aplastar toda forma de resistencia y que procedieron a la «detención de los principales militantes de izquierda», los cuales "fueron encarcelados en campos de concentración, interrogados y juzgados» para ser, luego de pocos meses, "liberados y deportados", mencionando sin extenderse, que el «doloroso episodio» implicó "secuelas de excesos y violaciones de derechos humanos» (p. 35).

El artículo proseguía con la Constitución aprobada en Chile en 1980, la cual, pese a no ser votada «en circunstancias políticas del todo normales», habría sido «respaldada adecuadamente por amplios sectores de la población» (p. 35). A partir de entonces, señalaba, la "lucha» continuó en "menor escala» y "restringida a los servicios de inteligencia y a los grupos clandestinos" que atacaban los altos mandos militares, agregando que la Iglesia Católica, además de brindar apoyo a las "víctimas de persecución política», habría logrado hacer escuchar sus denuncias por la «violación a los derechos humanos» (p. 35). Así, sugería, se habría iniciado un periodo caracterizado por el «retorno gradual a condiciones de paz» y la «reaparición [...] del debate político», además de un florecimiento económico «espectacular» eventualmente basado en la "seguridad" ofrecida a "la empresa privada y la inversión extranjera» (p. 35). A continuación, se mencionaban sin detalles las revueltas populares de los años ' 80 , el plebiscito de 1988, las elecciones presidenciales de 1989 y la continuación de Pinochet como
Comandante en Jefe de las Fuerzas Armadas y, más tarde, como "senador vitalicio». Finalmente, el texto concluía mediante la alusión a algunos logros de los gobiernos democráticos de Aylwin (1990-1994) y de Frei Ruiz-Tagle (1994-2000): la democratización de la arena política, la mejora de las condiciones sociales de los pobres, la investigación de violaciones a los derechos humanos, la compensación hacia algunas víctimas y el encarcelamiento de algunos jefes de la inteligencia militar del régimen pinochetista.

En resumen, se trataba de un escrito que, dando un amplio lugar a los clichés de la época, como el elogio de la herencia económica de los ' 80 y la satisfacción por la recobrada democracia, redundaba en múltiples fórmulas eufemísticas que desperfilaban el claro reconocimiento de los horrores de la violencia política ejercida por agentes del Estado en tiempos de dictadura. En el fondo, el artículo tendía a reproducir sin el menor espíritu crítico una historia oficial que, fruto de las distorsiones introducidas por formaciones de compromiso subsidiarias de la persistencia de los conflictos políticos y del temor al retorno de los militares, resultaba además edulcorada con pasajes dignos de una reseña turística promocionando las bondades de la desconocida localidad.

Airadas reacciones no tardaron en manifestarse y numerosos analistas, principalmente argentinos y franceses, expresaron su molestia mediante cartas al editor publicadas en el siguiente número del Newsletter. Diatkine (1998) protestó por un «artículo de vulgarización político-económica» que, buscando entregar una imagen "tranquilizadora» respecto de "conflictos que despertaron mucha rabia y dejaron huellas dolorosas», escamotea la palabra "dictadura» y nada «informa ni acerca de las condiciones de trabajo, ni sobre posibles ataques personales de los que hayan podido ser víctimas los psicoanalistas» ( $p$. 4). Canestri (1998) reprochó «que un exceso de 'neutralidad' puede resultar en una traición a la historia y a la sensibilidad democrática de muchos colegas", agregando que no aparece la palabra «dictadura», ni los términos "tortura» y "asesinato» (p. 4). Subrayaba que para muchos ser «interrogados» significó ser «torturados» y para varios ser «juzgados» implicó ser "salvajemente asesinados», mientras que los «liberados y deportados» fueron "perseguidos incluso en el exilio» o "simplemente asesinados en una explosión» (p. 4). Finalmente, Gampel (1998) criticó la necesidad de un psicoanalista de recurrir a la "historia oficial» y desligarse de su tarea de «ir tras la verdad» (p. 4), al tiempo que Braun y Puget (1998) denunciaron tergiversaciones, la justificación del golpe militar y el uso de «discursos pseudodemocráticos» portadores de «rasgos autoritarios y dictatoriales» (p. 4).

En el mismo número del Newsletter, Arrué (1998b) se defendió replicando que de ningún modo había pretendido desconocer los casi tres mil muertos y/o des- 
aparecidos, ni el ejercicio de la violencia extrema. No obstante, no se retractaba y, disculpándose por errores u omisiones, indicaba que "[u]n mayor uso de comillas habría expresado mejor mi pensamiento» (p. 5). Rechazaba la idea de que sus palabras fuesen eufemísticas o que relatasen la historia oficial, aunque ello no lo llevara a ocupar el término "dictadura» y prefiriera utilizar las expresiones «régimen militar» o "gobierno militar». Asimismo, reiteraba los elogios a la economía neoliberal implantada en aquella época, subrayando el consenso que existiría sobre este punto, indicando el creciente espíritu de reconciliación nacional y agregando que sus planteamientos resultaban concordantes con declaraciones de destacados opositores a Pinochet. Sin embargo, sostenía, no pensó «otorgarle al cuestionado artículo mayor pretensión que mi percepción y mis puntos de vista» y que, más allá de la neutralidad, sus palabras buscaban ser reflejo de «[I]a prudencia y el esfuerzo por la ecuanimidad» (p. 5).

En el siguiente número del boletín, se agregó una nueva carta crítica. En ella, Berman (1999) manifestaba su decepción ante la respuesta de Arrué e indicaba suponer que el consenso mencionado constituía una formulación anterior a la detención de Pinochet en Londres y que el deseo de perdonar en nombre de la «reconciliación nacional» no era algo compartido por todos los chilenos. Subrayaba que, lejos de constituir un "asunto interno" de Chile, "los temas de asesinato, la tortura, el secuestro y brutal persecución política constituyen problemas que afectan a toda la humanidad, por lo que ningún país tiene el mandato de 'perdonar y olvidar' tales fenómenos» (p. 4). Recordaba que, «[d]urante los años de la persecución nazi, la comunidad psicoanalítica internacional mantuvo la 'neutralidad', evitando el tema en sus revistas», agregando que "los analistas en todos los países deben enfrentar abiertamente los problemas más importantes en la historia de su país, cuando estas cuestiones tienen inevitables repercusiones psicológicas para sus analizandos y para su sociedad» (p. 4).

La polémica estaba desatada y ponía en riesgo el próximo Congreso, amenazado por la inasistencia de numerosos psicoanalistas, sobre todo argentinos, como expresión de protesta. A decir verdad, como lo muestran algunas de las entrevistas realizadas por Adams-Silvan (1998) a los miembros del Programme Committee, desde el comienzo existieron temores en torno a la participación, aunque enfocados en la asistencia europea y norteamericana. Los entrevistados manifestaban que Santiago podía resultar turísticamente menos atractivo que otras ciudades de Europa o Estados Unidos, agregando aprehensiones relacionadas a la lejanía, al costo de los pasajes y al invierno del hemisferio sur. A ello, se sumaban las casi premonitorias preocupaciones por problemas de índole político, al tiempo que la entrevistadora se inquietaba por la incomodidad que algunos pudiesen resentir con el pasado reciente de Chile, como habría sido el caso en el Congreso de 1991 en Buenos Aires. Pero las respuestas de los entrevistados, encaminadas a disolver tales obstáculos, no parecen haber ido en una dirección muy diferente a la del artículo de Arrué. En efecto, lejos de limitarse a argumentos académicos, científicos o profesionales, ellos resaltaban atractivos turísticos, subrayaban ofertas gastronómicas y culturales, destacaban la belleza del paisaje, las bondades del clima o la cordialidad de los chilenos, además de entregar una aliviadora efigie sobre la seguridad, la estabilidad política, el ambiente democrático, la próspera economía y el recuerdo, pero tan sólo el recuerdo, de los dolorosos sucesos acaecidos en dictadura.

Evidentemente, la polémica complicaba aun más las cosas: una firme rectificación no podía esperar. En el mismo Newsletter que publicara la carta de Berman, el editor dedicaba la sección Dialogue a un extenso dossier que, titulado "Violencia, Terror y Persecución», incluía (quizás en signo de desagravio) contribuciones de Canestri (1999) y de Puget (1999). Además, el Presidente de la IPA, Otto Kernberg, formado como médico y como psicoanalista precisamente en Chile, declaraba que en una reciente reunión realizada en Santiago había quedado «impresionado por la madurez general de los avances democráticos en el país» y por "el común repudio de los horribles actos criminales cometidos durante la dictadura», subrayando la «compartida decepción general con los regímenes, tanto de extrema izquierda como de extrema derecha» (1999, p. 5). Igualmente, agregaba dos anuncios: la disposición del Presidente de la República de Chile para inaugurar el Congreso; y la inclusión en éste de una sesión plenaria adicional, donde la proyección de un documental sobre un "desaparecido» por la dictadura chilena introduciría una discusión sobre «la responsabilidad psicoanalítica en el apoyo de la democracia y nuestra oposición a los regímenes totalitarios y militares» (p. 5)

Y, en efecto, así sucedió: el lunes 26 de julio de 1999 el Presidente Frei pronunció el discurso inaugural y, horas más tarde, un Cine Foro Especial exhibió el film Fernando ha vuelto (Caiozzi, 1998) para continuar con una mesa redonda que, presidida por el psicoanalista chileno Juan Pablo Jiménez, reunió intervenciones de Vamik Volkan, Afaf Mahfouz, Marcelo Viñar y Juan Francisco Jordán (Vetö, 2013). Pero, más allá de la efectividad de estas maniobras para destrabar la situación, una pregunta permanece: ¿cómo entender aquel polémico artículo de Arrué? Ciertamente, el texto parece revestir un marcado carácter sintomático, pero ¿sintomático de qué, de quién, de quiénes? ¿Cuál es el estatus de aquel episodio, cuáles sus resortes, cuál su naturaleza y su sentido? 
Si nos precipitamos pudiésemos cerrar el asunto resolviéndolo en una cuestión de puntos de vista personales, sean estos correctos o incorrectos. De hecho, se trata del expediente que el propio Arrué (1998b) utiliza cuando sostenía que su escrito sería solamente "la versión de un psicoanalista chileno» (p. 5). Sin embargo, no podemos contentarnos con esta solución, que más que explicar, justifica y deja las cosas en la más resuelta indeterminación. Además, variadas consideraciones parecen complejizar la respuesta y alejarnos del simple -incluso simplista- recurso a la opinión individual libre de subordinaciones.

\section{EL PATHOS DISCURSIVO DE LA HISTORIA OFICIAL}

Resulta llamativo que ningún analista chileno haya públicamente objetado o corregido aquel texto. De hecho, en el mismo número del boletín donde Arrué formulaba sus descargos, apareció una breve historia del psicoanálisis chileno que sólo hacía una escueta alusión a los "retornados del exilio» y la dictadura era únicamente sugerida por un impreciso alejamiento «de la Asociación de los avatares históricos que conmocionaron a muchas instituciones académicas chilenas» (Gomberoff, 1999, p. 17). Incluso el entonces presidente de la APCh, José Antonio Infante, y los copresidentes del Comité Organizador Local, Jiménez y Jordán, defendieron a su colega y al cuestionado artículo. Sostenían que ni ellos, ni ningún miembro de su Asociación, «han podido descubrir en el artículo una actitud empática o de aprobación hacia la dictadura o el régimen militar (términos para nosotros sinónimos) sufrido por el pueblo chileno durante 17 años", expresaban saber "lo que las palabras violación de los derechos humanos significan y no nos gusta alardear de ello porque también sabemos de la utilización política e ideológica de este sufrimiento». Preferían, entonces, «permanecer en silencio ante agonías humanas de esta naturaleza y elevar nuestras voces para exigir justicia y verdad cuando esto es posible», pues "lo que hemos ganado durante los últimos 9 años de democracia es demasiado precioso como para desperdiciarlo y obviamente deseamos protegerlo" (Infante, Jiménez y Jordán, 1999, p. 17).

Pero, el escamoteo o el franco silencio respecto de la dictadura no parecen haber sido excepción entre las expresiones públicas de miembros de la APCh. De hecho, la situación del país parece haber ya sido minimizada o normalizada desde el golpe militar mismo. Así lo insinúa el calmo tono de la respuesta de Whiting, presidente de la Asociación en aquel tiempo, a la carta del 2 de octubre de 1973 de Widlöcher, entonces secretario de la IPA: «Le agradezco muy sinceramente en forma personal y a nombre de nuestros asociados [...] las expresiones de afecto y apoyo [...] en conexión con los momentos difíciles porque pasaba nuestro país en aquellos días. Situación que al presente está perfectamente controlada y en ningún momento perturbó el normal desarrollo de nuestras actividades científicas y docentes $»^{1}$.

La misma situación reina en el corpus de textos con vocación histórica que, construido y socializado por la APCh a partir de 1980 , se ha instalado como historia oficial del psicoanálisis chileno en virtud de haberse producido en la institución psicoanalítica más antigua del país, la única reconocida por la IPA y la primera en establecer un relato histórico de la disciplina. No obstante, como toda historia institucional, se trata de un relato que ha tendido a hacer pasar su historia particular por la historia general, operando supresiones y obliteraciones de otros actores, iniciativas y narrativas psicoanalíticas ${ }^{2}$. Detengámonos, entonces, en las características de esta "historia oficial» y prestemos atención a la forma en que allí es referida la dictadura.

En 1980 se instala la primera piedra de lo que, casi una década después, constituirá el mencionado corpus. Fundada un año antes bajo la dirección de Jacobo Numhauser, la Revista Chilena de Psicoanálisis publica un escrito de Whiting (1980) que constituirá el texto inaugural de la historia del psicoanálisis chileno y que perdurará casi una década como la única publicación en su género. En rigor, no será sino hasta 1988 que, con los preparativos de la celebración de los cuarenta años de la APCh, el impulso de Whiting es prolongado por Arrué que, como presidente de la Asociación, promueve un trabajo de consolidación histórica institucional.

Respondiendo al Ilamado, entre 1988 y 1995, se suceden varios trabajos que consolidan la trama histórica fundada por Whiting-Arrué. En 1988, la revista de la APCh publica un artículo de Florenzano y, en 1989, otro de Prat Echaurren; en 1990, la Revista de Psiquiatría publica un texto de Gomberoff, y en 1991 aparece el libro Cuarenta años de Psicoanálisis en Chile que, editado por Casaula, Coloma y Jordán, incluye un nuevo escrito de Arrué y todo un grupo de artefactos de rememoración de los «pioneros»; dos años más tarde, la revista de la Asociación transcribe un coloquio (Davanzo, 1993) donde tres antiguos referentes -Prat, Davanzo y Ganzaraín- conversaban sobre la historia de la institución; y, para culminar, en 1995 el consolidado corpus histórico recibía reconocimiento internacional mediante la traducción y publicación de un artículo de Arrué (1991), incluido en un libro que recopilaba información histórica de las agrupaciones psicoanalíticas en el mundo. Luego, habrá que esperar ocho años y más para ver aparecer tres nuevos escritos: el mencionado texto de Gomberoff de 1999, uno de Davanzo (2005) y otro de Álvarez (2009). Entremedio, encontramos numerosos obituarios, homenajes, semblanzas y textos afines que, en lo esencial, siguen la misma orientación historiográfica. 
Ahora bien, el texto de Whiting (1980) establece la primera "periodización " $^{3}$ comenzando en 1910, con la conferencia de Germán Greve en Buenos Aires; prosigue con los regresos desde Europa de Allende Navarro en 1925 y de Matte Blanco en 1943, la obtención por este último de la Cátedra de Psiquiatría en la Universidad de Chile y la fundación de la APCh en 1949; pasa a otra etapa con la salida de los psicoanalistas de sus puestos universitarios y la emigración de Matte y otros en los sesenta; y finaliza en 1970 con la adquisición de la personalidad jurídica de la Asociación. Pero este trabajo, a semejanza del cual se escribirá toda la historia oficial del freudismo en Chile hasta la actualidad, no integra el contexto social, ni el trasfondo político, ni menos aún los temas culturales ligados a la recepción y al desarrollo del psicoanálisis en tierras chilenas. Quedándose en los hitos y pioneros institucionales, la historia de la disciplina resulta amputada de la historia social, política, económica y cultural del país. Si bien algunos de los textos subsiguientes agregan ciertos antecedentes e introducen episodios posteriores a 1970, todos mantienen la cronología establecida y, por regla general, jamás aparece la palabra "dictadura» o "tortura». Incluso en el último texto del corpus (Álvarez, 2009), publicado casi tres décadas después, los años ochenta aparecen mencionados somera y generalmente, sin lograr ser integrados al entramado histórico.

En 1988, Arrué adopta la periodización de Whiting hasta fines de 1960 y, para la UP, el golpe y la dictadura, propone continuarla integrando la situación política a una comprensión del desarrollo del psicoanálisis chileno. Sin embargo, su intento resulta fallido y, por el contrario, funda un pathos discursivo que, reproducido en adelante, se caracterizará básicamente por estrategias narrativas cargadas de eufemismos para referirse al período de la dictadura, por omisiones o ausencia de distinciones entre fenómenos evidentemente disímiles, por giros verbales enigmáticos, por imprecisas cronologías ad-hoc y por el intento de sustituir interpretaciones históricopolíticas usando otras, psicoanalíticamente inspiradas. Así, por ejemplo, en una sola página (la número 4) habla de grupos "probablemente vulnerados»o de "circunstancias conflictivas [...] al finalizar la década del 60», pero al no dar detalles no se sabe cuáles eran los grupos, ni por qué circunstancias fueron violentados. Del mismo modo, sin explicar a lo que alude, agrega que algunas de estas circunstancias fueron ajenas al "éxito de lo analítico» y, nuevamente sin aclaraciones, menciona la proximidad de «serios vaivenes sociopolíticos». Finalmente, refiere un misterioso "ajuste de cuentas» en donde se habría mezclado lo político con lo teórico, dejándonos sin poder adivinar ni qué teorías, ni qué posturas políticas, ni qué supuestas cuentas pendientes son referidas.
Por otra parte, el texto nombra a quienes se alejaron del movimiento psicoanalítico chileno, entregando indicaciones que resultan complejas por sus omisiones y falta de diferenciaciones. En tal sentido, se habla sin distingo del «doloroso fallecimiento de los Dres. Carlos Núñez y Gabriel Castillo» (p. 5), siendo que se trata de hechos situados en niveles distintos y acaecidos en condiciones muy diversas: lo de Núñez fue un suicidio (en 1984) desvinculado, al parecer, de asuntos políticos; lo de Castillo fue una desaparición (en 1976) que, aparentemente perpetrada por agentes de la Dirección de Inteligencia Nacional (DINA) del régimen pinochetista, está directamente ligada con la situación histórica, social y política de la dictadura (Vetö, 2013). Asimismo, el escrito hace mención a los Dres. Rosenblatt y Altamirano que, según el autor, se habrían alejado de la APCh por manifestar mayor interés en otras orientaciones no analíticas. Pero, con ello se esquivan las condiciones bajo las cuales Altamirano (el hermano de quien fuera Secretario General del Partido Socialista durante la UP) se retira de la Asociación alrededor de 1981, a su regreso del exilio. Si bien éste fue, luego, uno de los fundadores de una asociación de terapia familiar, él mismo señala que su distanciamiento nada tuvo que ver con una pérdida de interés por el psicoanálisis, sino con la incomodidad sentida allí luego de su retorno y, precisamente, por el sostenido silenciamiento de todo lo que se vinculara con política ${ }^{4}$.

Tampoco se menciona el periodo de dictadura en ninguno de los escritos que, producidos en los noventa, consolidan el corpus histórico oficial. En los trabajos de Florenzano (1988), Prat (1989) y Davanzo (1993) ni siquiera hay eufemismos; mientras que en los de Arrué $(1991,1995)$ y Gomberoff $(1990,1999)$ sólo se adivina en disfrazadas alusiones y términos como «cambios», "fenómenos» o "vaivenes sociopolíticos», sin hacer jamás uso de las más precisas expresiones "golpe de Estado», "dictadura», «tortura», "ejecuciones», "detenidos desaparecidos» o «presos políticos». Por su parte, los textos de los años 2000 en nada varían a este respecto, siguiendo fielmente la rutina de omisiones y escamoteos.

Ahora bien, para el primer grupo de textos, con excepción de Davanzo (1993), parece válido considerar que fueron producidos en condiciones dictatoriales, de suerte que no parece absurdo estimar que, en cierta medida, sus omisiones pudiesen tener relación con una protección frente a posibles represalias y persecuciones. Sin embargo, para el segundo grupo de escritos y, más aún, para el texto de Álvarez (2009), es necesario integrar nuevas hipótesis que permitan entender las elisiones. Para estos, ni el retorno de la democracia, ni los Informes de las Comisiones Nacionales de Verdad y Reconciliación (1991) y de Prisión Política y Tortura (2004), ni las sentencias judiciales a agentes de la dictadura, ni el arresto en 
Londres de Pinochet en 1998, parecen haber tenido la fuerza suficiente como para alejarlos de su atávica adhesión a la costumbre de omisión devenida verdadero pathos discursivo.

Así, por ejemplo, Gomberoff (1990) destacaba que «[h]asta 1973 hubo un grupo de psiquiatría infantil en el Hospital Calvo Mackenna, de orientación dinámica» (p. 382), suprimiendo que aquel servicio fue cerrado por albergar a un grupo que, encabezado por Altamirano, se identificaba con tendencias políticas de izquierda, además de pensar el psicoanálisis bajo las coordenadas de un compromiso social. Igualmente, en el mismo artículo, señala que «en 1974 en la Escuela de Psicología de la Universidad Católica quedaban sólo dos profesores, candidatos analistas, uno de los cuales dejó de serlo al poco tiempo» (p. 385), silenciando que uno de dichos profesores era Castillo, obligado a renunciar a su trabajo académico en 1975 y detenido desaparecido desde octubre de 1976. El texto prosigue señalando que, en la misma época, los analistas iniciaron un proceso de repliegue desde los distintos servicios públicos y departamentos universitarios, hacia la Asociación y sus consultas privadas. Intenta explicar el fenómeno en función de una eventual contradicción entre psicoanálisis y universidad, en relación a asuntos de vocación o de «identidad analítica», en virtud de duelos no resueltos, de cuestiones vinculadas al funcionamiento de grupos pequeños según Bion -ya aludidos por Florenzano (1988)-, de cuestiones de organización y de estilo estructural de la institución o, incluso, de la supuesta influencia del "matriarcado» y del lugar del padre dejado vacío. En contraste, no menciona que las universidades y los servicios públicos habían sido intervenidos por los militares, y que durante aquella época (y no sólo en Chile) las dictaduras privilegiaron enfoques -sobre todo en humanidades y ciencias sociales- donde se enfatizase menos la reflexión o la crítica, y más la adaptación, la conducta y el pragmatismo.

Ciertamente, hay quienes subrayan lo sucedido en el país desde los setenta hasta mediados de los ochenta (Arrué, 1991, 1995; Gomberoff, 1990). No obstante, en ellos no se distingue lo sucedido durante el gobierno de Frei Montalva y sus efectos sobre la APCh, de lo que pudo haber acontecido con el gobierno de Allende y, posteriormente, con el golpe y la dictadura. En tal sentido, Arrué (1991) señala que, en dicho periodo, "la situación socio-política de nuestro país naturalmente afectó a las personas de la Institución y en ciertos casos en forma muy dolorosa, sin embargo, a nivel del grupo, no pareció tener mayor trascendencia» (p. 44-5). Nada se dice sobre qué precisamente, en el transcurso de 25 años, afectó a las personas y no a la institución: ¿las reformas agraria y universitaria? ¿las transformaciones introducidas por la UP? ¿el golpe y la violencia? ¿la instalación de la dictadura y la violación de los derechos humanos? ¿la Constitución de 1980? Asimismo, tampoco se explica de qué modo fueron afectadas las personas: ¿les expropiaron tierras? ¿emigraron por desacuerdos con las políticas de Allende? ¿desaparecieron? ¿fueron exiliados? ¿fueron detenidos ilegalmente? ¿fueron exonerados? Por último, no se entrega ninguna explicación acerca de cómo la institución pudo permanecer incólume después del golpe y a pesar de los exilios, desapariciones, detenciones, paros, toques de queda o del permanente Estado de excepción de aquellos años.

En consecuencia, lejos de ser el producto de un esfuerzo de ecuanimidad y prudencia o de ser el fruto de tendenciosas y abusivas tergiversaciones, el polémico artículo de Arrué (1998) sería, en el fondo, tan sólo un engranaje más de un entramado muchísimo más vasto que sobrepasa acertadas o desacertadas apreciaciones personales. En efecto, la revisión del consolidado corpus histórico de la APCh parece indicar que el mencionado escrito no se reduce al mero antojo de algún punto de vista, pues muy por el contrario se encuentra enteramente atravesado por el pathos discursivo que, sostenidamente, ha animado la historia oficial del psicoanálisis en Chile.

\section{HISTORIAS MARGINALES AL INTERIOR DE LA APCH}

Pese a que el corpus histórico de la APCh se encuentra dominado por el mencionado pathos, existen otros textos producidos por miembros de dicha institución que, sin tratar directamente la historia del psicoanálisis, revelan otras perspectivas acerca del golpe y la dictadura. Estos trabajos, sin embargo, no circulan como referencias en la historia oficial y permanecen, por distintos motivos, en una cierta marginalidad.

El primero de ellos es un texto que, escrito en 1984 por Bruzzone, Casaula, Jiménez y Jordán (1991), aborda la "persecución», los sentimientos "paranoides» y los procesos "regresivos» experimentados por los autores durante su formación en el Instituto de la APCh en los años'80. Sorprendentemente, como si nada tuviese que ver con el asunto y pese a las evidentes semejanzas, la realidad sociopolítica chilena de aquellos años no aparece mencionada en el artículo, ni siquiera sugerida. Es, en cierto modo, como si ésta sólo hubiese podido emerger desplazada -a la manera de un "retorno de lo reprimido»-, sea en los análisis didácticos, supervisiones y seminarios, sea en los reglamentos y estructura institucionales.

Algo más explícito respecto de la situación de la época y sus consecuencias para el psicoanálisis, un trabajo de Hinzner y Noemi (1986) examina la cuestión de la «realidad externa» y su injerencia en la institución y la práctica psicoanalíticas, sugiriendo aquello que otros textos callan o no logran integrar. Sostiene que «un mundo externo caracterizado por una gran 
violencia, regido por la omnisciencia», inmodificable por el razonamiento y donde se perjudica la posibilidad de "discriminar entre lo verdadero y lo falso", afecta a los pacientes y a la tarea del psicoanalista, además de servir como modelo «inconscientemente incorporado en nuestras instituciones» para conducir «a 'silencios', sentimiento de soledad, dificultad para compartir experiencias» (p. 43). Propone, así, distinguir el rol del analista en sesión de aquel que le cabe como miembro de una institución, preguntándose por el papel que le corresponde a esta última respecto a dicha realidad altamente patógena.

Pero el texto que con mayor decisión se aleja del mencionado pathos, es un escrito de 1989 donde Jiménez (1991), sin eufemismos, omisiones o vaguedades, habla abiertamente de dictadura, detenciones ilegales, ejecuciones, degollamientos, persecuciones. Poniendo en duda la ilusión de mantener intactas la «abstinencia» y la «neutralidad» del analista en condiciones sociales dictatoriales como la chilena, examina la manera en que estas últimas inciden en la cotidianeidad para inmiscuirse problemáticamente en la clínica y en la transferencia, de suerte que «el conflicto político-ideológico irrumpe, al igual que un terremoto, en la sesión de análisis» (p. 455). En tal sentido, agrega el autor, las situaciones políticas extremas pondrían en riesgo la viabilidad del «encuadre» que, en el tratamiento psicoanalítico, propicia la capacidad de paciente y analista «de crear [...] un espacio y un tiempo que permita la toma de distancia de los eventos originariamente traumáticos, para reelaborarlos en el seno de una nueva experiencia» ( $p$. 456). Es que la intensificación de la violencia política atentaría contra aquel necesario «cierto grado de distanciamiento de la realidad actual y presente», pues o bien lo impide por su masivo ingreso en el análisis, o bien determina que su preservación inconmovible pueda «llegar hasta la negación o desmentida de la realidad actual» (p. 457).

Sin duda, estos tres textos entregan algunos jirones de una historia, otra historia, que parece haber quedado escamoteada en el relato oficial del psicoanálisis chileno. Sin embargo, no por ello estos escritos logran mantenerse enteramente ajenos al pathos discursivo dominante. En efecto, Bruzzone, Casaula, Jiménez y Jordán (1991) no alcanzan a establecer ningún vínculo con la manera en que las condiciones totalitarias pueden llegar a afectar a los analistas, a la institución analítica o al ejercicio del psicoanálisis. De hecho, cuando el texto fue preliminarmente presentado en el 150 Congreso Psicoanalítico de América Latina (Buenos Aires, 1984), algunos analistas argentinos observaron la eventual relación con la situación sociopolítica chilena y, sorprendidos, ninguno de los autores supo qué responder: simplemente nunca lo habían pensado así ${ }^{5}$. Asimismo, pese a destacar la resuelta incidencia de la «situación externa» sobre la práctica y la institucionalidad psicoanalíticas, Hinzner y Noemi (1986) tampoco explicitan a cuales «patógenas» «circunstancias actuales», cargadas de "violencia» y "omnisciencia», se refieren, dejándonos sin saber si se trata efectivamente de la dictadura o de, por ejemplo, la guerra fría y la amenaza nuclear.

Por cierto, el texto de Jiménez (1991), parece escapar a tal impronta discursiva. No obstante, incluso allí encontramos algo del mencionado pathos. De manera sintomática, la versión publicada en 1991 es dedicada a la memoria de Castillo, pero se omite indicar quién portaba aquel nombre y en qué circunstancias había fallecido. Además, la manera en que se examina la incidencia de la dictadura sobre la práctica analítica, termina por sumir al psicoanálisis en la más resuelta inoperancia frente a lo político. En función de una discutible disyunción entre "realidad externa» y "realidad interna» (también presente en el texto de Hinzner y Noemi), se restringe la política a la primera y se confina al psicoanálisis en la segunda, como si éste tuviese poco que ver con aquella. Se convoca, así, un lugar común en la literatura psicoanalítica de la época que, olvidando la formulación freudiana según la cual «desde el comienzo mismo la psicología individual es simultáneamente psicología social» (Freud, 1998b, p. 67), no parece reparar en el riesgo, frecuentemente formulado por Freud, de que la cura deje de estar acompasada "con el vivenciar real del paciente, y que así [...] pierda contacto con el presente» (Freud, 1998a, p. 129). De este modo, lo social y lo político serían extranjeros indeseables que, mediante un uso mañoso de las nociones de "abstinencia» y «neutralidad», deberían ser extirpados para allanar, mediante una neutralización de lo social y una abstención en lo político, un espacio enteramente apartado en el cual situar la práctica analítica. He aquí, nuevamente, uno de los tópicos característicos del pathos discursivo: la imagen de un psicoanálisis aislado que, en apariencia al menos, se vincula con el mencionado retiro social y político vivido en la APCh a partir de los años sesenta.

Finalmente, existen otros dos escritos que, aparecidos después del episodio de 1998, también pueden integrarse a este conjunto de trabajos. El primero es el libro de Capponi (1999), donde se busca integrar aspectos de las obras de Freud, Klein, Bion y Kernberg, para aplicarlos al esclarecimiento y eventual enfrentamiento del conflicto social que, según el autor, dividiría a la ciudadanía chilena post-dictatorial. Se trataría de un duelo inconcluso cuya elaboración sólo tendría lugar en los individuos y requeriría de líderes que, capaces de promover condiciones susceptibles de «disminuir al máximo la persecución y la culpa persecutoria de los grupos sociales y, por ende, los estados mentales paranoicos y maníacos» (p. 193), faciliten la progresión hacia configuraciones más «neuróticas» y, 
luego, «maduras». A diferencia del pathos, Capponi reconoce la violencia acaecida y formula, a su manera, el conflicto sociopolítico que ella supondría. No obstante, el espacio dedicado a la exposición histórica es asombrosamente ínfimo, resumiendo en 4 páginas (el libro contiene 228) el Informe de la Comisión Nacional de Verdad y Reconciliación (1991). Además, resulta igualmente llamativo que, prefiriendo expresiones amenguadas como «intervención de las Fuerzas Armadas» o "período militar», se omita el término "golpe» y sólo escuetamente se utilice la palabra «dictadura». Pero, quizás, el aspecto más crítico del libro sea la aplicación, directa y sin rigurosidad epistemológica alguna, de una teoría (kleiniana) del desarrollo mental temprano a la comprensión de acontecimientos sociales extremos con efectos traumáticos específicos. Tal como señala Scott (1999), ello redunda en una psicopatologización del problema sociopolítico y desplaza el análisis hacia el campo individual donde la acción política y social serían meros consortes de una superación personal de distorsiones maniacas o persecutorias. Más allá de los decididos reparos que, en distintos niveles, nos provoca el libro de Capponi (donde incluso se afirma que para la elaboración del conflicto bastaría la «actitud madura» de sólo una de las partes capaz de idar amor contra agresión!), es evidente que tampoco aquí está enteramente ausente la incidencia del pathos.

De manera por entero distinta, en el segundo texto, Díaz (2005) propone un modelo que, buscando abordar los traumas subjetivos específicamente derivados de la represión política en Chile, se apoya en una vasta experiencia clínica con víctimas de la dictadura llevada a cabo en el Instituto Latinoamericano de Salud Mental y Derechos Humanos (ILAS). Se trata de un trabajo que, escrito por un miembro de la APCh, aborda frontalmente las brutales consecuencias subjetivas y sociales del ejercicio de la violencia política, asumiendo implícitamente que, frente a tales fenómenos, el psicoanálisis se ha visto conceptualmente transformado para llegar a ser aplicado críticamente en el esclarecimiento de estos. Ciertamente, nada del pathos parece incidir en este texto. No obstante, pese a haber sido publicado en la revista de la Asociación, el artículo se caracteriza por llevar la impronta discursiva y políticamente comprometida propia del ILAS.

También cabría incluir aquí las comunicaciones presentadas por miembros de la APCh en el Cine Foro sobre Psicoanálisis y Derechos Humanos del Congreso de 1999 (Jiménez, 1999; Castillo, Colzani, Gómez \& Jordán, 1999). Curiosamente, ellas nunca fueron publicadas en la revista de la APCh, ni en ninguna de la IPA, sino que aparecieron en el primer número de la revista del ILAS.

\section{A MODO DE CONCLUSIÓN}

Pero, ¿qué pasiones tan vigorosas han podido sostener, y posiblemente aún sostienen, el mencionado pathos? Para responder esta pregunta resulta insuficiente recurrir al sólo examen crítico del corpus histórico sin considerar aspectos más globales. A decir verdad, el pathos discursivo que impregna el relato histórico oficial de la APCh no parece enteramente extranjero a la tradición política que, consolidada durante el nazismo, fue promovida por la IPA durante décadas. Dicha política podría definirse como: «defender y preservar la institución a cualquier precio y garantizar la supervivencia de todas y cada una de las sociedades psicoanalíticas que atravesaban dificultades» (Steiner, 2003, p. 42). Así, entre 1933 y 1936, la IPA promovió en la Sociedad Psicoanalítica de Berlín un principio de acomodación al régimen nazi (Nitzschke, 1992); en 1934, expulsó a Wilhelm Reich por sus compromisos con el marxismo (Roazen, 2001); en 1979, se negó a hacer una declaración oficial contra la violación de Derechos Humanos en América Latina, aduciendo que eran «rumores» (Vezzetti, 1999); entre 1973 y 1993, encubrió a Amilcar Lobo, torturador de la dictadura brasileña y candidato de la Sociedad Psicoanalítica de Río de Janeiro y a Leao Cabernite, su analista didacta y presidente de la misma asociación (Besserman, 1998). En consideración de ello, sería ingenuo pensar que el pathos discursivo de la APCh fuese el resultado de la pura creatividad de una institución acosada por sus propios fantasmas, olvidando el lugar que le cabe en una tradición de silenciamiento y pretendida neutralidad respecto de órdenes políticos capaces de amenazar la institucionalidad de la IPA.

Pero, más localmente, el discurso consolidado en la APCh sobre la dictadura tampoco resulta ajeno a la retórica chilena de la reconciliación que se re-elaboró como conjuro a partir de 1990, tanto desde los gobiernos de la coalición de centro-izquierda que gobernó después de la dictadura (Concertación de Partidos por la Democracia), como desde la derecha y las Fuerzas Armadas. Meciéndose entre el olvido moral y político, por un lado, y la justicia y verdad «en la medida de lo posible», por el otro, esta formación discursiva buscó tranquilizar a las víctimas sin alterar los acomodos institucionales y los precarios equilibrios obtenidos en 1990 (Lira \& Loveman, 2002). Como lo señalara el expresidente Aylwin (1996), «entendíamos que no podíamos centrar indefinidamente el debate nacional en escudriñar el pasado, porque esto significaría ahondar las divisiones que queríamos superar, postergar los grandes desafíos en el ámbito económico social y aún poner en riesgo el propio proceso de democratización» (p. 38).

A decir verdad, en las omisiones, obliteraciones y desfiguraciones que, respecto de los años de plomo, pueblan el pathos discursivo de la historia oficial del psicoanálisis chileno, resuenan con fuerza los ecos de aquellos silencios que, de acuerdo a Moulian (2002), impregnaron las estrategias de "blanqueo» del así lla- 
mado proceso de transición a la democracia instalado en Chile luego de la dictadura. Proceso en el cual, como lo señala Garcés (2010), «las fuerzas democráticas que tomaron el gobierno en 1990 generaron diversas estrategias de adaptación a la "transición pactada"» (p. 148), para mantener la «gobernabilidad» al precio de silenciar los dolores del pasado.

Omisión, eufemismo y olvido fueron, entonces, las acciones fundantes $-y$ fundamentales- del Chile de la transición, la cual operó «como un sistema de trueques: la estabilidad, se dijo, tiene que ser comprada por el silencio» (Moulian, 2002, p. 38); y donde «el consenso se convirtió en una conminación al silencio. Romperlo significaba situarse en un terreno dramático, cuya violación sería atentar contra el proceso (de transición), dañarlo (p. 44)». En consecuencia, sería ingenuo pensar que una comunidad de psicoanalistas hubiese podido escapar a aquella lógica dramática tan plagada de amenazas espectrales, demostrando que, incluso en su blando alegato por la ecuanimidad, la APCh en modo alguno se encontraba verdaderamente aislada: ella formaba parte, quizás en su extremo más ciego, del ilusorio argumento de la reconciliación nacional.

Ciertamente, estas breves indicaciones no agotan los múltiples elementos que han podido participar en el impulso y la mantención de esta patho-lógica configuración del discurso sobre la dictadura en la historia oficial del psicoanálisis chileno. En tal sentido, resultaría imprescindible examinar las condiciones efectivas en las que se encontraron los psicoanalistas chilenos y la institucionalidad analítica de la época, además de considerar las prácticas concretas del psicoanálisis en Chile, tanto a nivel de su transmisión como en el plano de su aplicación. No obstante, la estimación de dichas condiciones y de tales prácticas requiere de nuevas investigaciones, las cuales en todo caso necesitan formularse desde una perspectiva crítica, cultural y política, capaz de superar las sordas predisposiciones del pathos discursivo que ha dominado la historia del psicoanálisis chileno hasta nuestros días.

\section{NOTAS}

1 Carlos Whiting (1973, noviembre 2), Carta a Daniel Widlöcher. Archivo de la Asociación Psicoanalítica Chilena. Biblioteca de la Asociación Psicoanalítica Chilena.

2 En la historiografía de las ciencias, esto generalmente perdura hasta el surgimiento de relatos concurrentes. Actualmente han emergido perspectivas que, promoviendo una mirada crítica de la historia oficial, han revelado fragmentos de aquella otra historia que, hasta hoy, habían sido oscurecidos. Entre tales iniciativas se cuentan, además del presente escrito, las actuales investigaciones doctorales de Mariano Ruperthuz y de Silvana Vetö, Ilevadas

a cabo en la Universidad de Chile. Esperamos que, desde estos esfuerzos, puedan surgir otros corpus para el psicoanálisis chileno, inspirados en nuevas orientaciones y metodologías.

3 Este hecho es de inmensa relevancia dada la importancia que tiene la periodización en el trabajo histórico, como gesto de ordenamiento del campo. Su injerencia no sólo es metodológica, sino también profundamente ideológica (Stagnaro, 2006).

4 Guillermo Altamirano (2009, octubre 15). Comunicación personal.

5 Eleonora Casaula (2012, diciembre 13). Comunicación personal.

\section{BIBLIOGRAFÍA}

Adams-Silvan, Abby (1998), "I.P.A Congress - 25-30 July 1999 - Santiago de Chile. Interviews with the Members of the Programme Committee", Newsletter IPA. International Psychoanalysis, 7 (1), pp. 24-33.

Álvarez, Nelson (2009), "Algunas reflexiones sobre la formación de psicoanalistas en Chile", Revista Chilena de Psicoanálisis, 26 (2), pp, 145-159.

Arrué, Omar (1988), "40 años de psicoanálisis en Chile", Revista Chilena de Psicoanálisis, 7, pp. 3-5.

Arrué, Omar (1991). “Orígenes e identidad del movimiento psicoanalítico chileno" En: Casaula, Eleonora; Coloma, Jaime \& Jordán, Juan

Francisco (eds.), 40 años de psicoanálisis en Chile. Biografía de una Sociedad Psicoanalítica, Santiago de Chile, Ananké, pp. 25-54.

Arrué, Omar (1995), “Chile”. En: Kutter, Peter (ed.). Psychoanalysis International. A Guide to Psychoanalysis Throughout the World. Vol. 2 America, Asia, Australia, Further European Countries, Stuttgart-Bad Camstatt, Frommann Holzboog Verlag, pp.74-93.

Arrué, Omar (1998a), "Brief Note on the History of Chile in the Last Thirty Years", Newsletter IPA. International Psychoanalysis, 7 (1), pp. 34-35.

Arrué, Omar (1998b), "Omar Arrué responde a sus críticos”, Newsletter IPA. International Psychoanalysis, 7 (2), p. 5. 
Aylwin, Patricio (1996), La Comisión Chilena sobre la Verdad y Reconciliación. Serie: Estudios básicos de derechos humanos, VII. Dispoinible en: http://www.bibliojuridica.org/libros/4/1841/4. pdf [consultado el 11/05/2013]

Barthes, Roland (2004), Lo neutro: curso del Collège de France 1977-1978, Buenos Aires, Siglo XXI.

Berman, Emmanuel (1999), "Chile Once More", Newsletter IPA. International Psychoanalysis, 8 (1), p. 4

Besserman, Helena (1998), No se lo cuenten a nadie: política del psicoanálisis frente a la dictadura y la tortura, Buenos Aires, Polemos.

Braun, Julia \& Puget, Janine (1999), "Cartas al Editor. ¿Historia de Chile?", Newsletter IPA. International Psychoanalysis, 7 (2), p. 4.

Bruzzone, Mónica; Casaula, Eleonora; Jiménez, Juan Pablo \& Jordán, Juan Francisco (1991), "Regresión y persecución en la formación psicoanalítica. A propósito de una experiencia”. En: Casaula, Eleonora; Coloma, Jaime \& Jordán, Juan Francisco (eds). 40 años de psicoanálisis en Chile. Biografía de una Sociedad Psicoanalítica, Santiago de Chile, Ananké, pp. 371-379.

Caiozzi, Silvio (Director), (1998), Fernando ha vuelto [Documental], Santiago de Chile.

Canestri, Jorge (1998), “Cartas al editor. ¿Historia de Chile?”, Newsletter IPA. International Psychoanalysis, 7 (2), p. 4.

Canestri, Jorge (1999), "Dialogue by Jorge Canestri", Newsletter IPA. International Psicoanálisis, 8 (1), p. 28.

Capponi, Ricardo (1999), Chile, un duelo pendiente: perdón, reconciliación, acuerdo social, Santiago de Chile, Andrés Bello.

Casaula, Eleonora; Coloma, Jaime \& Jordán, Juan Francisco (eds.), (1991), Cuarenta años de psicoanálisis en Chile. Biografía de una sociedad científica. 2 Tomos, Santiago de Chile, Ananké.

Castillo, María Isabel; Colzani, Francesca; Gómez, María Elena \& Jordán, Juan Francisco (1999), "Presentación", Revista ILAS, I (1), pp. 24-26.

Comisión Nacional de Verdad y Reconciliación (1991), Informe de la Comisión Nacional de Verdad y Reconciliación, Santiago de Chile, Edición Oficial.

Comisión Nacional de Prisión Política y Tortura (2004), Informe de la Comisión de Prisión Política y Tortura, Santiago de Chile, Edición Oficial.

Davanzo, Hernán (1993), “Orígenes del psicoanálisis en Chile. Coloquio con Arturo Prat E. y Ramón Ganzaraín", Revista Chilena de Psicoanálisis, 10 (2), pp. 58- 65.

Davanzo, Hernán (2005), "Sobre la 'formación de candidatos' en el Instituto de psicoanálisis de la APCH", Revista Chilena de Psicoanálisis, 22 (1), pp. 5-18.

Diatkine, Dominique (1998), "Cartas al editor. ¿Historia de Chile?", Newsletter IPA. International Psychoanalysis, 7 (2), p. 4.

Díaz, Margarita (2005), “Efectos traumáticos de la represión política en Chile: una experiencia clínica", Revista Chilena de Psicoanálisis, 22 (1), pp. 19-28.
Freud, Sigmund (1998a), "Sobre la iniciación del tratamiento (Nuevos consejos sobre la técnica del psicoanálisis, I)", Obras completas. Vol. XII, Buenos Aires, Amorrortu.

Freud, Sigmund (1998b), "Psicología de las masas y análisis del yo" Obras completas. Vol. XVIII, Buenos Aires, Amorrortu.

Florenzano, Ramón (1988), "Estrategias de desarrollo y la Asociación Psicoanalítica Chilena", Revista Chilena de Psicoanálisis, 5, pp. 20-28.

Gampel, Yolanda (1998), "Cartas al editor. ¿Historia de Chile?”, Newsletter IPA. International Psychoanalysis, 7 (2), p. 4.

Garcés, Mario (2010), “Actores y disputas por la memoria en la transición siempre inconclusa”, Ayer, 79 (3), pp. 147-169.

Gomberoff, Mario (1990), "Apuntes acerca de la historia del psicoanálisis en Chile", Revista de Psiquiatría, 7, pp. 379-387.

Gomberoff, Mario (1999), "El psicoanálisis en Chile", Newsletter IPA. International Psychoanalysis, 7 (2), p. 5.

Hinzner, Helena \& Noemi, Carmen (1986), “Visión psicoanalítica de la realidad externa", Revista Chilena de Psicoanálisis, 3, pp. 35-43.

Infante, José Antonio, Jiménez, Juan Pablo \& Jordán, Juan Francisco (1999), "Carta a nuestros colegas psicoanalistas", Newsletter IPA. International Psychoanalysis, 7 (2), p. 17.

Jiménez, Juan Pablo (1991). "Algunas reflexiones sobre la práctica del psicoanálisis en Chile hoy". En: Casaula, Eleonora; Coloma, Jaime \& Jordán, Juan Francisco (eds.), 40 años de psicoanálisis en Chile. Biografía de una Sociedad Psicoanalítica, Santiago de Chile, Ananké, pp. 439-462.

Jiménez, Juan Pablo (1999), “Presentación”, Revista ILAS, I (1), pp. 19-20.

Kernberg, Otto (1999), "The President's Column", Newsletter IPA. International Psychoanalysis, 8 (1), pp. 5-6.

Lira, Elizabeth \& Loveman, Brian (2002), El espejismo de la reconciliación política: Chile, 1990-2002, Santiago, LOM.

Moulian, Tomás (2002), Chile actual, anatomía de un mito, Santiago, LOM.

Nitzschke, Bernd (1992), "La psychanalyse considérée comme une science "a»-politique", Revue internationale d'histoire de la Psychanalyse, 5, pp. 169-182.

Prat, Arturo (1989), "Historia de la psiquiatría dinámica en Chile", Revista Chilena de Psicoanálisis, 8, pp. 5-8.

Puget, Janine (1998), "Cartas al editor", Newsletter IPA. International Psychoanalysis, 7 (2), p. 4

Puget, Janine (1999), "Social violence: A psychoanalytical approach", International Psychoanalysis. IPA Newsletter, 8 (1), pp. 33-34.

Roazen, Paul (2001), The Historiography of Psychoanalysis, New Jersey, Transaction Publishers.

Scott, Catalina (1999), "Cartas al director", Revista chilena de psicoanálisis, 16 (2), pp. 107-112. 
Stagnaro, Juan Carlos (2006), "Evolución y situación actual de la historiografía de la psiquiatría en la Argentina”, Frenia, 7, pp. 7-37.

Steiner, Riccardo (2003), De Viena a Londres y Nueva York. Emigración de psicoanalistas durante el nazismo, Buenos Aires, Nueva Visión.

Vetö, Silvana (2013), Psicoanálisis en Estado de Sitio, Santiago, Ediciones El Buen Aire/ FACSO.
Vezzetti, Hugo (1999), "Instituciones psicoanalíticas en las dictaduras militares. Sumisión conformista a los poderes", Página 12 [en línea], disponible en: http://www.pagina12.com.ar/1999/ suple/psico/99-10/99-10-07/psico01.htm [consultado el 11/05/2013]

Whiting, Carlos (1980), "Notas para la historia del psicoanálisis en Chile", Revista Chilena de Psicoanálisis, 2, pp. 19-26. 